\title{
Linking Different Sustainable Development Goals (SDGs) via Food Production Diversity: A Comparative Study of Two Countries in Arabian Desert
}

\author{
By Dr. Suyu Liu ${ }^{1}$
}

\begin{abstract}
There is a growing interest of the linkages between different SDGs as the interactions between SDGs are more and more observed. Food production diversity's role in linking different SDGs deserves more attention, as it is directly related to a variety of SDGs such as SDG 1 (poverty reduction), SDG 2 (no hunger), and SDG 8 (economic growth and decent work). This article empirically examines the food production diversity in Saudi Arabia and Oman with Herfindal-Hirschmann Index, which measures food production diversity via the distribution of establishments and employees across 14 food production economic activities. It finds that in Saudi Arabia, the food production diversity is significantly lower and less changed than Oman. However, this may be caused by the much larger scale of food production in Saudi Arabia than Oman. Food production diversity is also possibly associated with cuisine culture, geographic location, and labor intensity in food production. However, there is insufficient evidence whether severe climate has an impact on food production diversity.
\end{abstract}

Keywords: SDGs; food production diversity; Herfindal-Hirschmann Index; Saudi Arabia; Oman

\section{Introduction}

Food production diversity is directly associated with various Sustainable Development Goals (SDGs). For example, it is linked with national and household incomes (Verma et al 2007), which is an important dimension of SDG 1 (poverty reduction). According to Kaulich (2012), it is also a sign which can reflect the sustainability of agriculture and manufacturing (SDGs 2 and 9), especially for countries which have severe climate conditions. This is particularly the situation for some resource-rich countries, which are taking efforts to reduce their dependence on natural resources and improve the overall economic diversity (SDG 8). In addition, due to the relatively lower technical requirements of food production, high food production diversity and consumption can benefit the agricultural development and enhance rural living standards (Ash 2006). This is because higher food production diversity can provide more food consumption choices and brings higher food security, which is especially important for countries with large and/or fast growing population (Ash 2014).

Hron et al (2007) classify diversification into three types: 1) concentric diversification, which adds new products and services related to the current business; 2) horizontal diversification, which adds new products and services not related to the current business, but for the needs of current customers; and 3) mixed diversification, which adds new 
products and services not related to the current business and customers. The majority of research on agriculture and food production diversification are within concentric diversification and mixed diversification, as the main types of food production diversification are adding new food products (Ash 2014) and moving towards non-food production activities (McNally 2001).

Motivations and obstacles of food production diversification have also been observed. One of the most significant motivations is to generate more income, which is directly associated with SDG 1. For example, Ilbery (1991) finds that income generation is the most often reason of food production diversification via a United Kingdom regional case study. This is supported by Bowler et al (1996) with another case study in the United Kingdom. However, McInerney and Turner (1993) argues that diversification may not necessarily lead to increase of income, especially if there is insufficient of market demand for the diversified products or services. This leads to further analysis of other motivating factors of food production diversification.

Hron et al (2008) identify that motivations of production diversitification for small and medium size agribusinesses in Czech Republic mainly include business enlargement, exploitation of unused (under-used) production factors, applications for subsidies or grants, and satisfaction of market demand. Bowler et al (1996) also support that responding to market, exploiting under-utilised farm resources, and creating job opportunities are important reasons of food production diversification, following the main motivation of income generation. Similarly, McInerney and Turner (1991) find that utilizing under-used resources or diverting resources in activities with higher expected returns, as well as reducing possible risks in relation to farming and food production are also main economic rationales of food production diversification. Buchta and Federicova (2010) use the case of Slovakia and demonstrate that the available public funding is a factor contributing to the food production diversification into non-agricultural activities.

A major obstacle of food production diversification is the size of the producer (farm). For example, as shown by Shucksmith and Smith (1991), on-farm diversification is more plausible and attractive for larger farms, as they may have more available capital and resources to redeploy. In contrast, smaller food producers usually have much limited available resource, especially under-utilised resources. This obstacle calls for the progress of achieving SDG 2, especially SDG Targets 2.3 and 2.a, which emphasize the increase of small-scale food producers' agricultural productivity and investment in rural infrastructure. Another obstacle of food production diversification is the institutional restrictions. Since food production diversification is linked with food security, governments may have policies to restrict the (over-) diversity of food production in order to ensure a sustainable supply of staple food, and also maintain a skilled workforce of food production. For example, restrictions on rural labour moving into urban regions exist in some countries (e.g. Ash and Kueh 1996), so that rural labour can keep sufficient skills in food production and hence the risk related to food security could be reduced. These policies may affect SDG Targets 2.b and 2.c, which aim to reduce restrictions on agriculture markets and promote the proper functioning of food commodity markets.

From the above-mentioned literature, three conclusions arise. First, it is revealed that there is a relationship between food production diversification and sustainability, income, and employment, which are reflected by different SDGs. Second, existing studies mainly 
examine food production diversification at the micro level (farm or household) while the macro level food production diversification (nation and industry) is less discussed. This is possible due to a lack of knowledge of suitable macro level data. Third, previous studies on food production diversity are mainly from the angle of agriculture instead of manufacture, so SDG 9 is less touched in existing literature of food production diversity. Fourth, food production diversity in countries with severe climate and less-developed agriculture and manufacturing is less discussed than in countries with strong agriculture development. This article aims to fill the gaps with evidence from Saudi Arabia and Oman, two resource-rich countries located in Arabian Desert.

\section{Materials and Methodology}

\subsection{Materials}

This article examines food production diversity in Saudi Arabia and Oman by investigating the distribution of two main production factors: materials and labour, across 14 economic activities under the category of manufacture of food products (United Nations Statistics Division 2008). Materials and labour are reflected by the amount of establishments and employees respectively. The data for Saudi Arabia is from its Industrial Performance Monitoring System, and data for Oman is from its National Dissemination and Analytical Portal. Both these databases were collaboratively developed by the national industrial statistical authorities and the United Nations Industrial Development Organization (UNIDO). At the time of submitting this article, the data have also been transferred into the UNIDO Statistics Data Portal (UNIDO 2020). This article selects the three years' data between 2014 and 2016 to avoid the significant disturbances of food production in these two countries caused by the unsustainable high oil price before 2014 and after 2018. They were also the most recent available data when starting to draft the article.

The selection of these two countries includes a number of reasons. First, both Saudi Arabia and Oman are regional influential countries. Saudi Arabia is the largest economy in the Middle East, and Oman has a widely-perceived regional and international influence due to its geographic location between Gulf of Oman, Gulf of Aden, and Arabian Sea. Second, both countries are trying to reduce their dependence on the oil sector and diversify their industries, in which food production is a priority. This provides a good opportunity to explore food production diversity with the perspective of SDG 9 instead of merely from the angle of SDG 2. Third, as two leading economies in the Middle East, these two countries have the highest data availability related to food production in that region.

\subsection{Methodology}

This article adopts Herfindal-Hirschmann Index (HHI) to examine the food production diversity. HHI is an index developed by Hirschmann (1945) and Herfindal (1950) with the original aim to examine market concentration and diversification. UNIDO and Deutsche Gesellschaft für Internationale Zusammenarbeit (GIZ) GmbH (2015) use $\mathrm{HHI}$ and normalized HHI (HHI*) to measure production diversification across different industries and economic activities. The relevant mathematical expressions are: $\mathrm{HHI}=\mathrm{S}_{1}{ }^{2}+\mathrm{S}_{2}{ }^{2}+\mathrm{S}_{3}{ }^{2}+\ldots+\mathrm{S}_{\mathrm{N}}{ }^{2}$ 
$\mathrm{HHI}^{*}=(\mathrm{HHI}-1 / \mathrm{N}) /(1-1 / \mathrm{N})$

where $S_{1}, S_{2}, S_{3} \ldots$ are the share of establishments and/or employees of economic activities $1,2,3$ in the whole industry of manufacture of food products. $N$ is the total number of economic activities in the whole industry. Since the industry of manufacture of food products has 14 economic activities (United Nations Statistics Division, 2008), in this context $\mathrm{N}=14$. The $\mathrm{HHI}$ can have values that range from $1 / \mathrm{N}$ to 1 , while $\mathrm{HHI} *$ has values of values ranging from 0 to 1 . For both $\mathrm{HHI}$ and $\mathrm{HHI}^{*}$, if the value is close to 1 , it indicates a low diversity.

The use of HHI is an application of this index into the measurement of production diversity, which may generate more evidence to support the expansion of HHI's applicability. The HHI is different from some other indices which explore food market and food availability, such as the Market Functionality Index developed by the World Food Programme (2020). This is because that the HHI used in this article is with the perspective of production diversity instead of market concentration. The use of $\mathrm{HHI}$ in this article does not have any intention to criticize other relevant indices. It is also consistent with the article's emphasis on the link between different SDGs, as food production is classified as manufacturing (SDG 9) while it is heavily relied on agriculture (SDG 2).

\section{Results and Discussion}

\subsection{Food production diversity in Saudi Arabia}

As shown in Tables 1 and 2, food production establishments and employees in Saudi Arabia are highly concentrated in the manufacture of bakery products. Between 2014 and 2016, over $63 \%$ of food production establishments are in the manufacture of bakery products, which is significantly higher than the rest of economic activities. Also, manufacture of bakery products employed near $40 \%$ of total workforce in the food production industry between 2014 and 2016. The food production diversity in Saudi Arabia is significantly lower in terms of employment than establishment. For example, the $\mathrm{HHI}^{*}$ value of food production establishment in Saudi Arabia between 2014 and 2016 was around 0.38 , while the $\mathrm{HHI}^{*}$ value of food production employment was only around 0.18 during the same period. During the three selected years, the food production diversity in Saudi Arabia remained very stable in terms of both establishment and employment.

Table 1: Distribution of Establishments across Economic Activities in the Industry of Manufacture of Food Products, Saudi Arabia, 2014-2016 (Unit: establishment)

\begin{tabular}{|l|c|c|c|}
\hline Year & $\mathbf{2 0 1 4}$ & $\mathbf{2 0 1 5}$ & $\mathbf{2 0 1 6}$ \\
\hline Economic Activity & Number (\%) & Number (\%) & Number (\%) \\
\hline Processing and preserving of meat & $656(5.82 \%)$ & $665(5.85 \%)$ & $687(5.82 \%)$ \\
\hline Processing and preserving of fish, crustaceans and mollusks & $34(0.30 \%)$ & $35(0.31 \%)$ & $36(0.30 \%)$ \\
\hline Processing and preserving of fruit and vegetables & $533(4.72 \%)$ & $542(4.77 \%)$ & $559(4.74 \%)$ \\
\hline Manufacture of vegetable and animal oils and fats & $126(1.12 \%)$ & $131(1.15 \%)$ & $133(1.13 \%)$ \\
\hline Manufacture of dairy products & $259(2.30 \%)$ & $266(2.34 \%)$ & $272(2.30 \%)$ \\
\hline Manufacture of grain mill products & $1219(10.81 \%)$ & $1230(10.82 \%)$ & $1276(10.81 \%)$ \\
\hline Manufacture of starches and starch products & $23(0.20 \%)$ & $24(0.21 \%)$ & $25(0.21 \%)$ \\
\hline Manufacture of bakery products & $7166(63.52 \%)$ & $7183(63.16 \%)$ & $7487(63.43 \%)$ \\
\hline Manufacture of sugar & $31(0.27 \%)$ & $32(0.28 \%)$ & $33(0.28 \%)$ \\
\hline Manufacture of cocoa, chocolate and sugar confectionery & $862(7.64 \%)$ & $877(7.71 \%)$ & $904(7.66 \%)$ \\
\hline Manufacture of macaroni, noodles, couscous and similar & $73(0.65 \%)$ & $75(0.66 \%)$ & $77(0.65)$ \\
\hline
\end{tabular}




\begin{tabular}{|l|c|c|c|}
\hline Year & $\mathbf{2 0 1 4}$ & $\mathbf{2 0 1 5}$ & $\mathbf{2 0 1 6}$ \\
\hline Economic Activity & Number (\%) & Number (\%) & Number (\%) \\
\hline farinaceous products & & & \\
\hline Manufacture of prepared meals and dishes & $3(0.03 \%)$ & $3(0.03 \%)$ & $3(0.03 \%)$ \\
\hline Manufacture of other food products n.e.c. & $230(2.04 \%)$ & $241(2.12 \%)$ & $243(2.06 \%)$ \\
\hline Manufacture of prepared animal feeds & $66(0.59 \%)$ & $68(0.60 \%)$ & $70(0.59 \%)$ \\
\hline Manufacture of food products (Total) & $\mathbf{1 1 2 8 1 ( 1 0 0 \% )}$ & $\mathbf{1 1 3 7 2 ( 1 0 0 \% )}$ & $\mathbf{1 1 ~ 8 0 4}(\mathbf{1 0 0} \%)$ \\
\hline HHI & $\mathbf{0 . 4 2 8}$ & $\mathbf{0 . 4 2 4}$ & $\mathbf{0 . 4 2 7}$ \\
\hline HHI* & $\mathbf{0 . 3 8 4}$ & $\mathbf{0 . 3 7 9}$ & $\mathbf{0 . 3 8 3}$ \\
\hline
\end{tabular}

Note: the sources of data in all tables in this article are introduced in the Section 2.1

Table 2: Distribution of Employment across Economic Activities in the Industry of Manufacture of Food Products, Saudi Arabia, 2014-2016 (Unit: individual)

\begin{tabular}{|l|c|c|c|}
\hline & $\mathbf{2 0 1 4}$ & $\mathbf{2 0 1 5}$ & $\mathbf{2 0 1 6}$ \\
\hline Economic Activity & Number (\%) & Number (\%) & Number (\%) \\
\hline $\begin{array}{l}\text { Processing and preserving of meat } \\
\text { Processing and preserving of fish, }\end{array}$ & $7624(7.36 \%)$ & $8134(7.41 \%)$ & $8258(7.37 \%)$ \\
\hline rrustaceans and mollusks & $401(0.39 \%)$ & $441(0.40 \%)$ & $438(0.39 \%)$ \\
\hline Processing and preserving of fruit and vegetables & $8197(7.91 \%)$ & $8476(7.72 \%)$ & $8803(7.86 \%)$ \\
\hline Manufacture of vegetable and animal oils and fats & $1275(1.23 \%)$ & $1330(1.21 \%)$ & $1373(1.23 \%)$ \\
\hline Manufacture of dairy products & $24253(23.41 \%)$ & $26061(23.73 \%)$ & $26325(23.50 \%)$ \\
\hline Manufacture of grain mill products & $4481(4.32 \%)$ & $4719(4.30 \%)$ & $4837(4.32 \%)$ \\
\hline Manufacture of starches and starch products & $97(0.09 \%)$ & $103(0.09 \%)$ & $105(0.09 \%)$ \\
\hline Manufacture of bakery products & $41470(40.02 \%)$ & $43401(39.52 \%)$ & $44685(39.88 \%)$ \\
\hline Manufacture of sugar & $920(0.89 \%)$ & $955(0.87 \%)$ & $989(0.88 \%)$ \\
\hline $\begin{array}{l}\text { Manufacture of cocoa, chocolate and } \\
\text { sugar confectionery }\end{array}$ & $10122(9.77 \%)$ & $11303(10.29 \%)$ & $11107(9.91 \%)$ \\
\hline $\begin{array}{l}\text { Manufacture of macaroni, noodles, couscous } \\
\text { And similar farinaceous products }\end{array}$ & $2036(1.97 \%)$ & $2088(1.90 \%)$ & $2182(1.95 \%)$ \\
\hline Manufacture of prepared meals and dishes & $210(0.20 \%)$ & $231(0.21 \%)$ & $230(0.21 \%)$ \\
\hline Manufacture of other food products n.e.c. & $1664(1.61 \%)$ & $1697(1.55 \%)$ & $1780(1.59 \%)$ \\
\hline Manufacture of prepared animal feeds & $862(0.83 \%)$ & $891(0.81 \%)$ & $926(0.83 \%)$ \\
\hline Manufacture of food products (Total) & $\mathbf{1 0 3 6 1 2 ( 1 0 0 \% )}$ & $\mathbf{1 0 9} \mathbf{8 3 0}(\mathbf{1 0 0} \%)$ & $\mathbf{1 1 2} \mathbf{0 3 7}(\mathbf{1 0 0 \% )}$ \\
\hline HHI & $\mathbf{0 . 2 3 9}$ & $\mathbf{0 . 2 3 7}$ & $\mathbf{0 . 2 3 9}$ \\
\hline HHI* & $\mathbf{0 . 1 8 1}$ & $\mathbf{0 . 1 7 9}$ & $\mathbf{0 . 1 8 0}$ \\
\hline
\end{tabular}

\subsection{Food production diversity in Oman}

As shown in Tables 3 and 4, both HHI and HHI* in food production diversity in Oman are close to 0 , which indicates a relatively high food production diversity. For example, the $\mathrm{HHI}^{*}$ of food production employment in Oman is only 0.077 in 2015.

Table 3: Distribution of Establishments across Economic Activities in the Industry of Manufacture of Food Products, Oman, 2014-2016 (Unit: establishment)

\begin{tabular}{|l|c|c|c|}
\hline & $\mathbf{2 0 1 4}$ & $\mathbf{2 0 1 5}$ & $\mathbf{2 0 1 6}$ \\
\hline Economic Activity & Number (\%) & Number (\%) & Number (\%) \\
\hline Processing and preserving of meat & $2(2.50 \%)$ & $2(2.94 \%)$ & $2(2.90 \%)$ \\
\hline Processing and preserving of fish, crustaceans and mollusks & $14(17.50 \%)$ & $11(16.18 \%)$ & $12(17.39 \%)$ \\
\hline Processing and preserving of fruit and vegetables & $6(7.50 \%)$ & $7(10.29 \%)$ & $7(10.14 \%)$ \\
\hline Manufacture of vegetable and animal oils and fats & $2(2.50 \%)$ & $2(2.94 \%)$ & $3(4.35 \%)$ \\
\hline Manufacture of dairy products & $2(2.50 \%)$ & $2(2.94 \%)$ & $2(2.90 \%)$ \\
\hline Manufacture of grain mill products & $2(2.50 \%)$ & $2(2.94 \%)$ & $2(2.90 \%)$ \\
\hline
\end{tabular}




\begin{tabular}{|l|c|c|c|}
\hline & $\mathbf{2 0 1 4}$ & $\mathbf{2 0 1 5}$ & $\mathbf{2 0 1 6}$ \\
\hline Economic Activity & Number (\%) & Number (\%) & Number (\%) \\
\hline Manufacture of starches and starch products & $2(2.50 \%)$ & $1(1.47 \%)$ & $1(1.45 \%)$ \\
\hline Manufacture of bakery products & $30(37.50 \%)$ & $24(35.29 \%)$ & $23(33.33 \%)$ \\
\hline Manufacture of sugar & $0(0.00 \%)$ & $0(0.00 \%)$ & $0(0.00 \%)$ \\
\hline Manufacture of cocoa, chocolate and sugar confectionery & $1(1.25 \%)$ & $1(1.47 \%)$ & $1(1.45 \%)$ \\
\hline $\begin{array}{l}\text { Manufacture of macaroni, noodles, couscous and similar } \\
\text { farinaceous products }\end{array}$ & $1(1.25 \%)$ & $1(1.47 \%)$ & $1(1.45 \%)$ \\
\hline Manufacture of prepared meals and dishes & $1(1.25 \%)$ & $1(1.47 \%)$ & $1(1.45 \%)$ \\
\hline Manufacture of other food products n.e.c. & $14(17.50 \%)$ & $12(17.65 \%)$ & $11(15.94 \%)$ \\
\hline Manufacture of prepared animal feeds & $3(3.75 \%)$ & $2(2.94 \%)$ & $3(4.35 \%)$ \\
\hline Manufacture of food products (Total) & $\mathbf{8 0 ( 1 0 0 \% )}$ & $\mathbf{6 8 ( 1 0 0 \% )}$ & $\mathbf{6 9 ( 1 0 0 \% )}$ \\
\hline HHI & $\mathbf{0 . 2 1 3}$ & $\mathbf{0 . 1 9 8}$ & $\mathbf{0 . 1 8 4}$ \\
\hline HHI* & $\mathbf{0 . 1 5 2}$ & $\mathbf{0 . 1 3 6}$ & $\mathbf{0 . 1 2 1}$ \\
\hline
\end{tabular}

Table 4: Distribution of Employment across Economic Activities in the Industry of Manufacture of Food Products, Oman, 2014-2016 (Unit: individual)

\begin{tabular}{|l|c|c|c|}
\hline & $\mathbf{2 0 1 4}$ & $\mathbf{2 0 1 5}$ & $\mathbf{2 0 1 6}$ \\
\hline Economic Activity & Number (\%) & Number (\%) & Number (\%) \\
\hline Processing and preserving of meat & $1078(0.39 \%)$ & $1082(10.47 \%)$ & $1108(10.71 \%)$ \\
\hline Processing and preserving of fish, crustaceans and mollusks & $920(8.87 \%)$ & $939(9.08 \%)$ & $858(8.29 \%)$ \\
\hline Processing and preserving of fruit and vegetables & $836(8.06 \%)$ & $915(8.85 \%)$ & $953(9.21 \%)$ \\
\hline Manufacture of vegetable and animal oils and fats & $760(7.33 \%)$ & $861(8.33 \%)$ & $299(2.89 \%)$ \\
\hline Manufacture of dairy products & $726(7.00 \%)$ & $780(7.54 \%)$ & $169(1.63 \%)$ \\
\hline Manufacture of grain mill products & $506(4.88 \%)$ & $590(5.71 \%)$ & $582(5.63 \%)$ \\
\hline Manufacture of starches and starch products & $224(2.16 \%)$ & $209(2.02 \%)$ & $226(2.18 \%)$ \\
\hline Manufacture of bakery products & $3183(30.69 \%)$ & $2927(28.31 \%)$ & $3333(32.22 \%)$ \\
\hline Manufacture of sugar & $0(0.00 \%)$ & $0(0.00 \%)$ & $0(0.00 \%)$ \\
\hline Manufacture of cocoa, chocolate and sugar confectionery & $349(3.37 \%)$ & $337(3.26 \%)$ & $388(3.75 \%)$ \\
\hline $\begin{array}{l}\text { Manufacture of macaroni, noodles, couscous and } \\
\text { similar farinaceous products }\end{array}$ & $139(1.34 \%)$ & $134(1.30 \%)$ & $102(0.99 \%)$ \\
\hline Manufacture of prepared meals and dishes & $48(0.46 \%)$ & $51(0.49 \%)$ & $53(0.51 \%)$ \\
\hline Manufacture of other food products n.e.c. & $459(14.07 \%)$ & $1371(13.26 \%)$ & $2144(20.73 \%)$ \\
\hline Manufacture of prepared animal feeds & $143(1.38 \%)$ & $143(1.38 \%)$ & $129(1.25 \%)$ \\
\hline Manufacture of food products (Total) & $\mathbf{1 0 3 7 1}$ & $\mathbf{1 0 3 3 9}$ & $\mathbf{1 0 3 4 4}$ \\
\hline HHI & $\mathbf{0 . 1 5 4}$ & $\mathbf{0 . 1 4 3}$ & $\mathbf{0 . 1 8 0}$ \\
\hline HHI & $\mathbf{0 . 0 8 9}$ & $\mathbf{0 . 0 7 7}$ & $\mathbf{0 . 1 1 7}$ \\
\hline
\end{tabular}

In comparison with Saudi Arabia, HHI and HHI* in Oman are sharply lower, and fluctuated more significantly. For example, the HHI* in terms of establishment in food production in Oman dropped from over 0.15 in 2014 to near 0.12 in 2016, and this figure for Saudi Arabia remained around 0.38 in the three consecutive years. However, similar as in Saudi Arabia, the largest amount of establishments and employees are concentrated in the manufacture of bakery products, which absorbs around $1 / 3$ of food production establishments and workforce. Nevertheless, these figures are much lower than in Saudi Arabia.

The relatively higher food production diversity can be partially explained by the fact that Oman has a more diverse cuisine culture, which is influenced by several other cuisines due to its cross-road location and history (Khan et al 2013). In addition, processing and preserving of fish products in Oman also have a significant share in its manufacturing of 
food products, which is also directly related to Oman's good access to sea.

A striking finding is that although food production diversity in Oman is higher than in Saudi Arabia, the imbalanced distribution of employment and establishments in Oman is also significantly because of its much smaller size of food production. For example, there were only 80 food production establishments in Oman in 2014, which dropped to 68 and 69 in 2015 and 2016 respectively. In such small number of food production establishments, even the distribution looks more equal across economic activities, the absolute amount of establishments in each economic activity is tiny. For example, there was no establishment and employment in the manufacture of sugar in Oman at all between 2014 and 2016, and there was only one establishment in the manufacture of prepared meals and dishes with around 50 employees during the same period. This suggests that the size of food production industry has a significant influence on its diversity.

Manufacture of bakery products shares a large proportion of establishments and employees in both Saudi Arabia and Oman. This is possibly because of bakery products are still the staple food for both countries, especially in Saudi Arabia, due to the customers' increasing knowledge of bakery products' health advantages, and thus the growing demand for whole wheat, reduced-sugar, and gluten-free bakery products (Agriculture and AgriFood Canada 2017). According to the results of Agriculture and Agri-Food Canadan (2017), there were 411 new bakery products launched in Saudi Arabia between 2014 and 2016.

In both countries, the distribution of establishments and the distribution of employees across economic activities are not consistent. For example, in Saudi Arabia, over 63\% food production establishments were within the manufacture of bakery productions, while it absorbed only around $40 \%$ of food production workforce. Similarly, only near $2.3 \%$ food production establishments were in the manufacture of dairy products in Saudi Arabia, but it employed more than $23 \%$ of the food production workforce. This could be explained by the different labour intensity across economic activities. For example, calculated from Tables 1 and 2, each establishment in manufacture of bakery products in Saudi Arabia employed on average around 5.8 employees, while on average an establishment in manufacture of dairy products in Saudi Arabia had around 94 employees. The labour intensity of food production establishments in Saudi Arabia and Oman differed sharply as well. For example, as calculated from Tables 3 and 4, in 2015, each food production establishment in Oman had around 152 employees, whereas on average a food production establishment in Saudi Arabia employed only 9.7 employees in the same year as calculation from Tables 1 and 2. This could be evidence which suggests that labour intensity is also linked with food production diversification.

This article supports the argument that food production diversity is associated with a number of SDGs. For example, as discussed above, food production diversity is possibly affected by labour intensity, and is therefore associated with SDG 8 which has a focus on decent work. The significant share of processing and preserving of fish products in Oman may be affected by the country's good access to sea, which demonstrates the possible impact on food production diversity by SDG 15. Similarly, as health advantage is a possible reason of the two countries' concentration of establishments and employees in the producing bakery products, the connection between food production diversity and SDG 
3 can be inferred. The analysis also supports the existing literature emphasizing on the interactions across SDGs (e.g., Nilsson et al 2016; Liu 2020), and does not consider different SDGs with a segemented and single disciplinary perspective. For example, as food production diversity is linked and affected by a number of different SDGs, it is difficult to have a comprehensive understanding of food production diversity from the angle of only one SDG, even that SDG (e.g., SDG 2 which focus on agriculture and food) may be perceived to have very strong association with food production diversity.

\section{Conclusion}

The main contribution of this article to existing literature is that it uses industrial level data to examine food production diversity in the perspective of establishment and labour distribution, with the support of $\mathrm{HHI}$ and $\mathrm{HHI}^{*}$ which are widely-used to measure market concentration but seldom in the field of production diversification. This article also promotes research on food production diversity with a joint perspective of both manufacturing and agriculture. It also improves the knowledge of agriculture and industrial production in the Middle East, where the agricultural development is popularly perceived as a challenge due to severe geographic conditions such as the wide coverage of desert. The potential link between food production diversity and different SDGs is examined in the article. It is found that a number of SDGs have possible impact on the food production diversity in Oman and Saudi Arabia. For example, the knowledge of health advantages of bakery products, which is related to SDG 3, may become a reason of the concentration of establishments and employees in the manufacture of bakery products in these two countries.

Evidences from two novel data sources reveal that food production diversity in Oman is significantly higher than in Saudi Arabia, but this may be largely due to Oman has a much smaller scale of food production than Saudi Arabia. It therefore suggests the scale of food production may has an impact on its diversity. In addition, food production diversity is also influenced by cuisine cultures and geographic locations. This can be reflected by the dominance of manufacture of bakery products in both countries, and the significant share of employment and establishments in processing and preserving fish products in Oman, which also suggests a possible relationship between food production diversity and SDG 15. Labour intensity may also be associated with food production diversity as shown by the comparison between Oman and Saudi Arabia, which shows a potential connection between SDG 8 and food production diversity. More research about such relationships should be encouraged with evidence from these two and also other countries. There is no evidence whether severe climate becomes a factor of food production diversification, as the two countries in Arabian Desert without fundamental difference in climate have significantly different levels of food production diversity. More comparisons between countries with sharply different climates may provide more information on the relationship between food production diversity and climate, as focused by SDG 13.

This article is of course not without limitation, which creates spaces for future research. First, due to the limited over-year data, it is difficult to examine the changes of food production diversity. In future when more data becomes available, it is suggested to conduct more cross-year comparisons with time series analysis. Second, future studies may 
compare the findings at both macro and micro levels, in order to generate more academic findings and practical implications. In addition, comparisons between food production diversity in developed and developing economies may be conducted in future to explore the relationship between food production diversity and economic development, as largely reflected in SDGs 1, 8, 9, and 12. Other scholars may also be interested in exploring the market competition and food production diversity in these two countries. For example, in the diary sector there are influential vertically integrated suppliers, as shown in an empirical study (Faye et al 2014), in Northern Saudi Arabia, dairy value chain is only widely known for the largest diary farms. However it is beyond the scope of this article.

\section{Acknowledgement}

The author appreciates insights and encouragement from colleagues and former colleagues at UNEP and UNIDO. The author's work experience at UNEP and UNIDO enriches the author's knowledge of food production biodiversity. The views expressed in this article are however the author's and do not represent the official stance of the United Nations and/or its subordinated organizations and/or agencies including UNEP and UNIDO, unless otherwise specified or referenced. This article is the author's research output and should not be considered as an official work output or a commissioned task of the United Nations and/or its subordinated organizations and/or agencies including UNEP and UNIDO.

\section{References}

Agriculture and Agri-Food Canada (2017) Sector Trend Analysis - Bakery Products in Saudi Arabia. Available at http://www.agr.gc.ca/eng/industry-markets-and-trade/international-agri-food-market-intelligence Lreports/sector-trend-analysis-bakery-products-in-saudi-arabia/?id=1492624260835\#1 (Accessed 4 October 2019)

Ash R. (2006) Squeezing the peasants: grain extraction, food consumption and rural living standards in Mao's China. The China Quarterly, 188: 959-988

Ash R. (2014) A new line on food security. China Economic Quarterly, 18: 45-48

Ash R. and Kueh, Y.Y., (eds.), (1996) Agricultural Development in China Since 1978. Oxford: Clarendon Press.

Bowler I., Clark G., Crockett A., Ilbery B., Shaw A. (1996) The development of alternative farm enterprises: a study of family labour farms in the Northern Pennines of England. Journal of Rural Studies, 12: 285295

Buchta S., Federicova Z. (2010) Diversification into non-agricultural activities under the conditions of Slovakia. Agricultural Economics- Czech, 56: 284-291

Faye B., Madani H. and El-Rouili S. A.H. (2014) Camel milk value chain in Northern Saudi Arabia. Emirates Journal of Food and Agriculture. 26(4): 359-365. 10.9755/ejfa.v26i4.17278

Herfindahl O. (1950). Concentration in the U.S. Steel Industry. Dissertion. Columbia University, New York.

Hirschmann A. (1945) National Power and the Structure of Foreign Trade. University of California Press and Cambridge University Press, California and London: 85-162

Hron J., Macak T., Huml J. (2009) Design of the diversification classifier for agricultural entrepreneurs activities. Agricultural Economics- Czech, 55: 565-570

Hron J., Stusek J., Arnost M., Huml J. (2008) Diversification strategy in small and medium size agribusinesses in the Czech Republic- impulses for searching business opportunities. Agricultural Economics- Czech, 54: 505-509

Hron J., Stusek J., Arnost M., Huml J., Platilova-Vorlickova L. (2007) Diversification- strategy of building the competitive advantage in agribusiness. Agricultural Economics- Cz̨ech, 53: 580-584 
Ilbery B.W. (1991) Farm diversification as an adjustment strategy on the urban fringe of the West Midlands. Journal of Rural Studies, 7: 207-218

Kaulich F. (2012) Diversification vs. specialization as alternative strategies for economic development: can we settle a debate by looking at the empirical evidence? United Nations Industrial Development Organization Working Paper, 3: 1-59

Khan A., Akhtar, S., Al-Matrushi, A.M. Fauquet, C.M., Briddon, R.W. (2013) Introduction of East African cassava mosaic Zanzibar virus to Oman harks back to "Zanzibar, the capital of Oman", Virus Genes, 46, 1: 195-198

Liu, S. (2020) Interactions between industrial development and environmental protection dimensions of Sustainable Development Goals (SDGs): Evidence from 40 countries with different income levels, Environmental \& Socio-economic Studies, 8, 3: 60-67

McInerney J., Turner M. (1991) Patterns, performance and prospects in farm diversification. University of Exeter, United Kingdom

McInerney J., Turner M. (1993) Agricultural adjustment in West Somerset. University of Exeter, Exeter, United Kingdom

McNally S. (2001) Farm diversification in England and Wales- what can we learn from the farm business survey? Journal of Rural Studies, 17: 247-257

Nilsson, M., Griggs, D., Visbeck, M. (2016) Map the interactions between Sustainable Development Goals. Nature, 534: 320-322

Shucksmith, D.M., Smith, R. (1991) Farm household strategies and pluriactivity in upland scotland. Journal of Agricultural Economics, 4, 3: 340-353

UNIDO (2020), INDSTAT 4 Industrial Statistics Database at 3- and 4-digit level of ISIC Revision 3 and 4. Vienna. Available from http://stat.unido.org.

UNIDO and GIZ (2015) EQuIP Tool 4: Diversification-Domestic and Export Dimensions, version 1.0 Available from http://www.equip-project.org/wp-content/uploads/2015/08/EQuIP Tool-4 V150821.pdf

United Nations Statistics Division (2008) International Standard Industrial Classification of All Economic Activities, Revision 4. Available from https://unstats.un.org/unsd/publication/seriesm/seriesm 4rev4e.pdf

Verma M.R., Datta, K.K., Mandal S., Tripathi, A.K. (2007) Diversification of food production and consumption patterns in India. Journal of Agricultural \& Food Information, 8: 87-100

World Food Programme (2020) Market Functionality Index: Technical Guidance. Rome, Italy. Available from https://docs.wfp.org/api/documents/WFP-0000114503/download/? ga=2.59105645.17860057 $\underline{36.1609255771-1807714056.1605474903}$ 